\title{
TRAP220 is modulated by the antineoplastic agent 6-Mercaptopurine, and mediates the activation of the NR4A subgroup of nuclear receptors
}

\author{
K D Senali Abayratna Wansa and George E O Muscat
}

Institute for Molecular Bioscience, University of Queensland St Lucia, 4072 Queensland, Australia

(Requests for offprints should be addressed to G.Muscat@imb.uq.edu.au)

\begin{abstract}
The NR4A1-3 (Nur77, NURR1 and NOR-1) subfamily of nuclear hormone receptors (NRs) has been implicated in Parkinson's disease, schizophrenia, manic depression, atherogenesis, Alzheimer's disease, rheumatoid arthritis, cancer and apoptosis. This has driven investigations into the mechanism of action, and the identification of small molecule regulators, that may provide the platform for pharmaceutical and therapeutic exploitation. Recently, we found that the purine antimetabolite 6-Mercaptopurine (6-MP), which is widely used as an anti-neoplastic and anti-inflammatory drug, modulated the NR4A1-3 subfamily. Interestingly, the agonist-mediated activation did not involve modulation of primary coactivators' (e.g. p300 and SRC-2/GRIP-1) activity and/or recruitment. However, the role of the subsequently recruited coactivators, for example CARM-1 and TRAP220, in 6-MP-mediated activation of the NR4A1-3 subfamily remains obscure. In this study we demonstrate that 6-MP modulates the activity of the coactivator TRAP220 in a dose-dependent manner. Moreover, we demonstrate that TRAP220 potentiates NOR-1-mediated transactivation, and interacts with the NR4A1-3 subgroup in an AF-1-dependent manner in a cellular context. The region of TRAP220 that mediated 6-MP activation and NR4A interaction was delimited to amino acids 1-800, and operates independently of the critical PKC and PKA phosphorylation sites. Interestingly, TRAP220 expression does not increase the relative induction by 6-MP, however the absolute level of NOR-1-mediated trans-activation is increased. This study demonstrates that 6-MP modulates the activity of the NR4A subgroup, and the coactivator TRAP220.
\end{abstract}

Journal of Molecular Endocrinology (2005) 34, 835-848

\section{Introduction}

Nuclear hormone receptors (NRs) function as ligandactivated transcription factors that regulate gene expression involved in reproduction, development and general metabolism (Gronemeyer \& Laudet 1995). NRs function as the pipeline between environmental stimuli and gene expression, effecting physiological changes. The importance of NRs in human physiology is underscored by the extensive range of therapeutics that have been created to combat disorders associated with dysfunctional hormone signalling. These diseases affect every discipline of medicine (Chawla et al. 2001). The importance of the NR4A1-3 (Nur77, NURR1 and NOR-1) subfamily of NRs as potential therapeutic targets for disease was made through the discoveries that Nur77, NURR1 and NOR-1 were implicated in Parkinson's disease, schizophrenia, manic depression, atherogenesis, Alzheimer's disease, rheumatoid arthritis, cancer and apoptosis (Murphy \& Conneely 1997, Borghaei et al. 1998, Saucedo-Cardenas et al. 1998, Backman et al. 1999, Labelle et al. 1999, Schimmel et al. 1999, Buervenich et al. 2000, Newman et al. 2000, Chen et al. 2001, Monajemi et al. 2001, Arkenbout et al. 2002,
Liu et al. 2002, McEvoy et al. 2002, Maltais et al. 2002, Wu et al. 2002, Kim et al. 2003, Le et al. 2003).

All members of the NR superfamily display a highly-conserved structural organisation, with an amino terminal region $\mathrm{AB}$ that encodes activation function 1 (AF-1); followed by the $\mathrm{C}$ region which encodes the DNA binding domain (DBD); a linker region $\mathrm{D}$ and the C-terminal E region. The DE region encodes the ligand binding domain (LBD) and a transcriptional domain, denoted as activation function 2 (AF-2) (Gronemeyer \& Laudet 1995). The NR4A1-3 subfamily of orphan nuclear receptors is well conserved in the DBD $(\sim 91-95 \%)$ and the C-terminal LBD $(\sim 60 \%)$, but divergent in the $\mathrm{N}$-terminal $\mathrm{AB}$ region (e.g. $\mathrm{AF}-1)$.

A decade ago, gene products were identified that appeared to belong to the nuclear receptor superfamily on the basis of their nucleic acid sequence identity. The endogenous signalling molecules which bound to these proteins were unknown and thus the term 'orphan receptor' was adopted. Thus the orphans forecast an enormous yet unexploited opportunity for the discovery of important new therapeutic agents.

6-Mercaptopurine (6-MP) belongs to the thiopurines, a group of substances structurally related to endogenous 
purine bases like adenine, guanine, and hypoxanthine. Azathioprine (parent compound of 6-MP) and other thiopurine drugs have been administered in the treatment of leukaemia and a number of autoimmune conditions, such as lupus erythematosus, pemphigus, and myasthenia gravis. More recently their use has been extended to the management of patients with chronic inflammatory bowel diseases (IBDs) including Crohn's disease and ulcerative colitis, and also multiple sclerosis. However, the precise mechanism of action of the thiopurine drugs remains unclear, despite more than 40 years of use. (Cara et al. 2004). It has been shown that this purine anti-metabolite has anti-proliferative and cytotoxic effects resulting primarily from the inhibition of purine de novo biosynthesis at multiple steps and incorporation into nucleic acids as thioguanine nucleotides (Cara et al. 2004).

Our previous work has expanded the function of purine anti-metabolites by demonstrating that 6-MP targets the NR4A1-3 subfamily of NRs and regulates its activity (Ordentlich et al. 2003, Wansa et al. 2003). This suggested that the signalling pathways that inhibit proliferation via inhibition of de novo purine and/or nucleic acid biosynthesis are involved in the regulation NR4A1-3 activity. The absence of a conventional ligand binding pocket in the NR4A1-3 LBD may account for the inability of $6-\mathrm{MP}$ to directly bind to the NR4A1-3 subfamily (Baker et al. 2003, Wang et al. 2003). 6-MP is a specific activator of the NR4A1-3 subfamily of NRs, as FXR, RXR, LXR $\alpha, \mathrm{ROR} \alpha$ and $\mathrm{ER} \alpha$ are not activated by 6-MP (Ordentlich et al. 2003). Furthermore general transactivators (GALVP16), and the myogenic transactivators (MyoD, Myogenin and MFE2C), and the coactivators steroid receptor coactivator-2 (SRC-2) and p300 are not activated by 6-MP (Wansa et al. 2003).

Ligand-dependent transcriptional activation by NRs is a process that involves a stepwise recruitment of various coactivators to the promoters of hormone-regulated genes assembled into chromatin. Ligand-dependent recruitment of the p160 factors (SRCs) in concert with other factors such as CREB binding protein (CBP), p300, p300/CBP-associated factor (PCAF), and coactivator-associated arginine methyltransferases 1(CARM1) bring histone acetyltransferase and histone methylation activity to NR complexes. The resulting modification of chromatin structure facilitates the recruitment of the thyroid receptor-associated proteins/ vitamin $\mathrm{D}$ receptor-interaction proteins (TRAP/DRIP) complex, helping to recruit RNA polymerse II to the promoters of the hormone regulated-genes. (Glass \& Rosenfeld 2000).

In this study, we determined whether the auxiliary coactivators CARM1 and TRAP220/DRIP205 could be modulated by 6 -MP. The results here identify $6-\mathrm{MP}$ as a regulator of TRAP220 activity. Moreover, we demonstrate that TRAP220 interacts with the NOR-1 and Nur77 in an AF-1-dependent manner. The region of TRAP220 that mediates 6-MP activation was delimited to amino acids 1-800. This study demonstrates that 6-MP not only mediates activation of the NR4A1-3 subfamily, but also modulates TRAP220 activity.

\section{Material and methods}

\section{Transient transfections}

Proliferating C2C12 cells were grown in DMEM supplemented with 10\% Serum supreme foetal calf serum (Biowhittaker, Edward Kellar Pty Ltd, Hallam, Victoria, Australia) in 6\% CO2 . Cells grown in 12-well dishes to $50 \%$ confluence were transiently transfected with $1 \mu \mathrm{g}$ (per well) POMC-TK-LUG (NurRE-5 $5_{\text {Pomc }}$-tkLUG) reporter plasmid (Maira et al. 1999) together with $0 \cdot 16 \mu \mathrm{g}$ (per well) pSG5-NOR-1-FL or pSG5 cotransfected with pcDNA-TRAP220 $(0.01,0.1$ and $0.3 \mu \mathrm{g}$ per well) alone using a DOTAP/Metafectene (Biotex Laboratories, GmbH, Munich, Germany) liposome mixture in HEBS (42 mM HEPES, $275 \mathrm{mM} \mathrm{NaCl}$, $10 \mathrm{mM} \mathrm{KCl}, 0 \cdot 4 \mathrm{mM} \mathrm{Na} \mathrm{HPO}_{4}$ and $11 \mathrm{mM}$ Dextrose, $\mathrm{pH} 7 \cdot 1)$. The DNA/DOTAP/Metafectene mixture was added to the cells in $1 \mathrm{ml}$ phenol red free DMEM, containing $10 \%$ charcoal-stripped foetal calf serum and incubated for $14 \mathrm{~h}$. Medium was replaced 16-24 h later and/or 6-MP (Sigma) was added and cells grown for a further $24-48 \mathrm{~h}$. Cells were harvested after $48 \mathrm{~h}$ and assayed for luciferase activity.

\section{GAL4 hybrid assay}

C2C12 cells were passaged into 12-well plates and transfected at $50-80 \%$ confluence with the reporter, G5E1b-LUC $(0 \cdot 33-1 \mu \mathrm{g}$ per well), and $0 \cdot 16 \mu \mathrm{g}$ (per well) of the GAL chimeric constructs SV40-GAL4 DBD, CMV-GAL4 DBD， GAL-NOR-1-FL， GMV-GALCARM1, GAL-TRAP220 and the chimeric constructs GAL-TRAP220-aa1-1000， GAL-TRAP220-aa1-800, GAL-TRAP220-aa1-300, GAL-TRAP220-aa330-660, GAL-TRAP220-aa660-970, GAL-TRAP220-aa9701300, GAL-TRAP220-aa330-1567, GAL-TRAP220aa1290-1567, GAL-TRAP220-aa800-1567, GALTRAP220S656A/S657A, GAL-TRAP220S756A/ S757A and GAL-TRAP220S796A/S797A. Furthermore, C2C12 cells were transfected with $0 \cdot 33-1 \mu \mathrm{g}$ (per

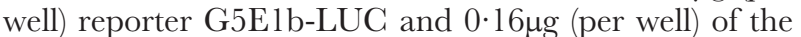
GAL chimeric constructs CMV-GAL4 DBD, CMVGAL-NOR-1-FL and GAL-TRAP220aa-1-1000 and were then cotransfected with either pcDNA-SRC-2, pcDNA-TRAP220 or SG5-NOR-FL $(0 \cdot 66 \mu \mathrm{g}$ per well) using DOTAP/Metafectene liposome mixture in HEBS per well. The DNA/DOTAP/Metafectene mixture was added to the cells in $1 \mathrm{ml}$ of DMEM, containing $10 \%$ 
FCS, and incubated for $14 \mathrm{~h}$. Medium was replaced 16-24 h later and/or 6-MP (Sigma) was added and cells grown a further $24-48 \mathrm{~h}$. Cells were harvested after $48 \mathrm{~h}$ and assayed for luciferase activity. Phenol red-free DMEM containing 10\% CSF was used for transfections with 6-MP in the procedure, as described previously (Wansa et al. 2002, 2003).

\section{Mammalian two-hybrid assay}

Plasmids $(1 \mu \mathrm{g}$ per well G5E1b-LUG reporter and $0.33 \mu \mathrm{g}$ per well GAL4 DBD or GAL-TRAP220 chimeric constructs) were co-transfected/expressed in human choriocarcinoma JEG3 cells grown in 12-well plates with either VP160, VP16-NOR-1 or VP16-Nur77 chimeric constructs $(0.33 \mu \mathrm{g}$ per well $)$ in DMEM containing 5\% charcoal-stripped FCS by the DOTAP/ metafectene-mediated procedure as described previously, then assayed with respect to their ability to transactivate the reporter (G5E1b-LUG) (Chen et al. 2000).

\section{Luciferase assays}

Luciferase activity was assayed using a Luclite kit (PerkinElmer Pty Ltd, Rowville, Victoria, Australia) according to the manufacturer's instructions. Briefly, cells were washed once in PBS and resuspended in $80 \mu \mathrm{l}$ phenol red-free DMEM and $80 \mu \mathrm{l}$ Luclite substrate buffer. Cell lysates were transferred to a 96-well plate and relative luciferase units were measured for $5 \mathrm{sec}$ in a Wallac Trilux 1450 microbeta luminometer (PerkinElmer, Wansa et al. 2002, 2003).

\section{Plasmids, plasmid construction and primer sequences}

The expression plasmids SV40 GALO (Kato et al. 1990), GMVGAL0, (Gasanova et al. 1994, Willy et al. 1995), pCMV-GAL-GARM1, pGMV-SRC-2 (Chen et al. 2000, 2002), pcDNA-TRAP220 (Rachez \& Freedman 2000), GAL-NOR-FL (Wansa et al. 2003) and the reporter plasmid G5E1b-LUC (Lillie \& Green 1989) have been described elsewhere. All primers used in this study were obtained from GeneWorks Pty Ltd, Thebarton, South Australia, Australia. CMV-GAL-NOR-1-FL was constructed by excising NOR1 cDNA from pSG5-NOR-FL and recloning into the EcoRI site of the GMVGAL0 vector. 5' GGG GTC GAC AT ATG CGC TGG GTG CAA GCG CAG and 3' GCG GTC GAC TCA GAA AGG CAG GGT GTC AAG GAA primers containing SalI sites were used to PCR NOR-1 cDNA; and 5' GCG GTG GAG AT ATG CGG TGT ATT CAA GGT CAA and 3' GGG GTC GAC TCA GAA AGA CAA TGT GTC CAT primers containing Sall sites were used to PGR Nur77 cDNA from pSG5-NOR-FL and pSG5-Nur77-FL expression plasmids, respectively . The PGR products were cloned into the SalI site of SV40-VP160. 5'GCG GTC GAC AT ATG GCC TGC GTG CAA GCC CAG and 3' GCG GTC GAC TCA TGT GGG TTG CGG AGA TGA TGA were used to PGR and clone NOR-1-AB and 5' GGG GTC GAC AT ATG GTT AAG GAA GTT GTG CGT and 3' GGG GTC GAC TCA GAA AGG CAG GGT GTC AAG GAA primers were used to PGR and clone NOR-1-DE. 5' GGG GTG GAC AT ATG CGG TGT ATT CAA GCT CAA and 3' GCG GTC GAC TCA CTC GCT GCG ACG TGA AGC CCG were used to PCR and clone Nur77-AB and 5' GCG GTG GAC AT ATG CGG CGG AAC CGG TGC CAG and 3' GCG GTG GAC TCA GAA AGA GAA TGT GTC CAT were used to PGR and clone Nur77-DE. PGR products were amplified from pSG5-NOR-1-FL and pSG5Nur77-FL expression plasmids and the cloned SalI site of SV40-VP160. Bold type indicates restriction enzyme sites.

Primers used for PCR amplification of TRAP220 sub-domains cloned into SV40 GAL0 were: TRAP220aal-800 GMUQ 805 5' GCG GTG GAC ATA TGA GTT CTG TCG TGG AAG G and GMUQ 807 3' GGG GTC GAC CTA ATG CGG AGA GCT TGA AG; TRAP220aal-330- GMUQ 808 5' GCA TCG ATA CGA TGA GTT GTC TCG TGG AAC G and GMUQ 809 3' GGG GAG CTC CTA CTG AGT GAT CAG TTC ATA C; TRAP220aa800-1567GMUQ 810 5' GCA TGG ATA GGA TGT CTC AGA GTA GCG and GMUQ 811 3' GGG GAG CTC CTA ATT CGG AAT CAG GGG C; TRAP220aal2901567-GMUQ 812 5' CCA TCG ATA CCA TGG TGA TAG ATA AAG TG and GMUQ 811 3' TRAP220aa330-660-GMUQ 813; 5' GCG GAA TTC ACG ATG TTT GAG GTA TCA AAG G and GMUQ 814 3' GGG GAA TTC GTA GGG GGG TGA GCG GGA; TRAP220aa 660-970-GMUQ 815 5' GCG GAA TTG AGG ATG GAA ATA TGG TGG GGG and GMUQ 816 3' GGG GAA TTG CTA GGT GCG ATT GCG TTC C; TRAP220aa970-1300-GMUQ 817 5' GCG GAA TTC ACG ATG AGT AAT AGT ACT CTC and GMUQ 818 3' GCG GAA TTG CTA GAG AAC CGG ATG CTT C; TRAP220aa330-1567GMUQ 813 5' and GMUQ 819 3' GGG GAA TTG CTA ATT GGG AAT CAG GGG. TRAP220aal1000 has been described elsewhere (Harris et al. 2002). Bold type indicates the nucleotides mutated on TRAP220.

\section{Site directed mutagenesis}

Using Stratagene Quick change site directed mutagenesis kit as per manufacturers' instructions (Stratagene, Cedar Creek, Texas, USA), GAL-TRAP220-aa1-800 chimeras 
that simultaneously carried double amino acid mutations were constructed. The primers were TRAP220S656A/ S657A-5' C CGT TTA GAA AGG CAG AAG GCG GGT TCG GGG TCA CGC GG and 3' GG GGG TGA GGG GGA AGC GGC GTT GTG CGT TTC TAA AGG G; TRAP220S756A/S757A- 5' GG ATG GTC CGA CTA GGC GCT TCA GAC AGG ATT GGG CG and 3' GG GCG AAT GGT GTC TGA AGG GGG TAG TCG GAC GAT CG; TRAP220S796A/S797A - 5' CG CGT CTT CGA GAT GCT GGA AGG TGT GGG CAT TCT CAG and 3' CTG AGA ATG CGC AGA GCT TGG AGC ATG TCG AAG AGG GG.

\section{Results}

\section{6-MP modulates the activity of TRAP220/DRIP205}

Previously we demonstrated that general transcriptional activators, myogenic trans-activators, and the primary coactivators, SRC-2 and p300, were not 6-MP targets (Wansa et al. 2003).

In the current study we investigated whether any subsequently recruited cofactors in the NR4A activation could be modulated by 6-MP. We utilised the GAL4 hybrid system, whereby putative activation domains are fused to the DBD of the yeast transcription factor GAL4. If these regions encode a modular activation domain, they complement the GAL4 DBD to produce a functional transactivator and induce the transcription of the GAL-responsive reporter construct G5E1b-LUG. G5E1b-LUG contains five copies of the GAL4 binding site upstream of a minimal E1b promoter. The coactivators, CARM1 and TRAP220, were fused to the GAL4 DBD and were examined for the ability of these chimeras to regulate the expression of the G5E1 bLUC reporter in C2G12 myogenic cells in the presence and absence of 6-MP (Fig. 1A). We observed that 6-MP did not activate the cofactor CARM1, however, the coactivator TRAP220 which contained amino acids 1-1000 was significantly activated by $6-\mathrm{MP}$ (Fig. 1B). This suggested that 6-MP modulated the activity of TRAP220.

To investigate the dose-dependent nature of 6-MPmediated modulation of TRAP220 we examined the ability of TRAP220 relative to NOR-1 to be activated by $0 \cdot 1-100 \mu \mathrm{M}$ 6-MP. GAL-NOR-FL and GALTRAP220 were responsive to 6 -MP at concentrations of $10 \mu \mathrm{M}$ and the activity of these chimeras was further potentiated at concentrations of $33 \mu \mathrm{M}, 50 \mu \mathrm{M}$ and $100 \mu \mathrm{M}$ (Fig. 1G). Thus, NOR-1 and TRAP220 were both modulated by 6 -MP. The EC50 values were in the range of $33-50 \mu \mathrm{M}$, however, at those concentrations 6-MP produced a more efficacious activation of NOR-1 relative to TRAP220.

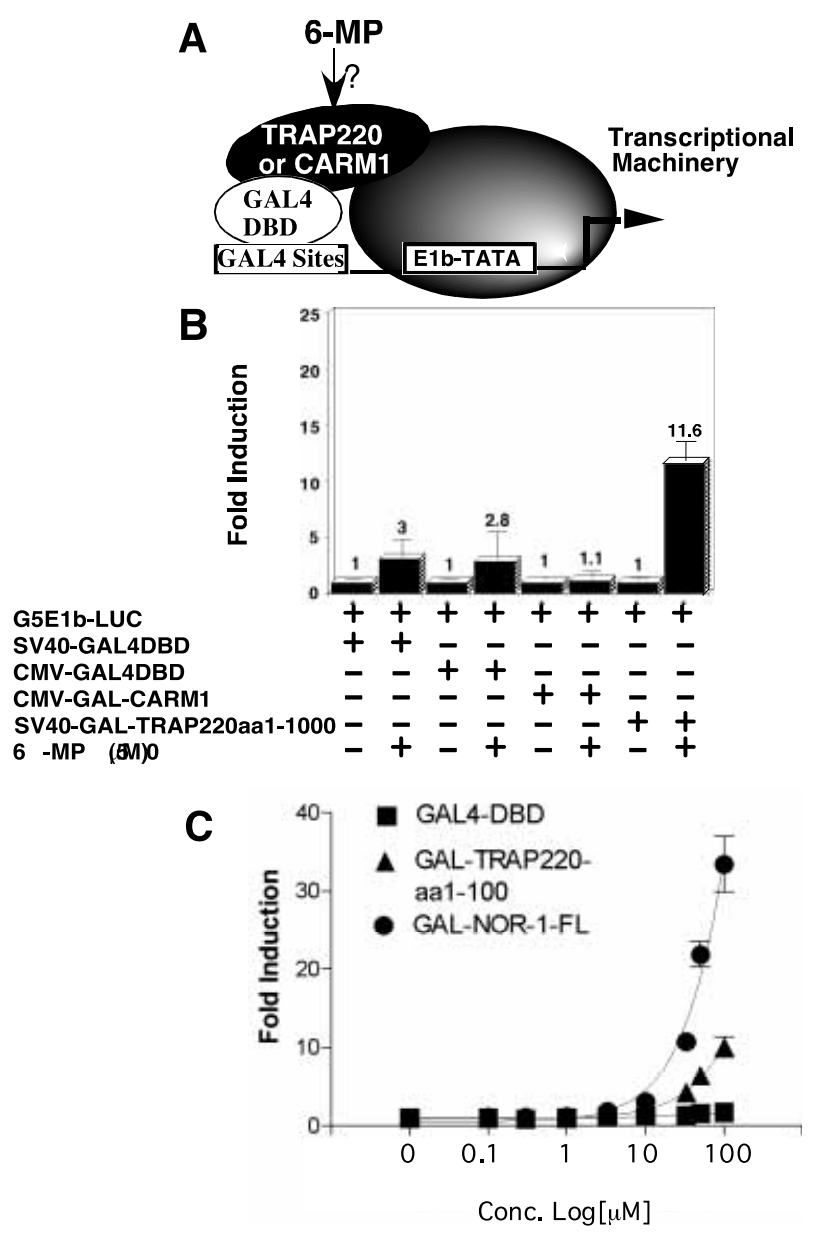

Figure 1 6-MP modulates the activity of TRAP220/DRIP205. (A) A diagrammatic representation of the Gal4 hybrid assay is shown. (B and C) GAL-TRAP220-aa1-1000, GAL-CARM1 and GAL-NOR-1-FL $(0.16 \mu \mathrm{g})$ were co-transfected into C2C12 proliferating myoblasts together with the reporter plasmid G5E1b-LUC $(0.83 \mu \mathrm{g})$ in presence and absence of $50 \mu \mathrm{M}$ of 6-MP. (C) Dose response activity to 6-MP is shown for GAL4-DBD, GAL-NOR1-FL and GAL-TRAP220-aa1-1000 at concentrations of $0.1,0.3,1,3.3,10,33,50$ and $100 \mu \mathrm{M}$. Fold induction is expressed as the difference in fold activation obtained after cotransfection of a GAL-chimeric construct in the presence of 6-MP relative to the same GAL-chimeric construct trasnsfected in the absence of 6-MP. The mean luciferase fold activation/induction and S.D. values (bars) were derived from a minimum of 2-3 independent triplicate experiments.

\section{The region between amino acids 1-800 of TRAP220 mediates the activation by 6 -MP}

In order to further characterise the region of TRAP220 that is activated by $6-\mathrm{MP}$, we constructed a comprehensive set of TRAP220 deletions by PCR and cloned these segments into the GAL4 DBD (Fig. 2A) and examined the ability of these chimeras to regulate the expression/ transcription of the G5E1b-LUG reporter in the presence and absence of 6-MP. In the GAL4 hybrid 
TRAP220-FL

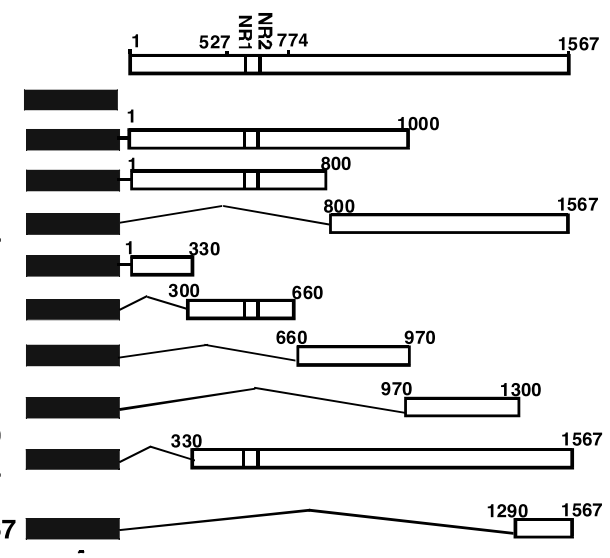

B

SV40-GAL4DBD

GAL-TRAP220-aa1-1000

GAL-TRAP220-aa1-800

GAL-TRAP220-aa800-1567

GAL-TRAP220-aa1-330

GAL-TRAP220-aa330-660

GAL-TRAP220-aa660-970

GAL-TRAP220-aa970-1300

GAL-TRAP220-aa330-1567

GAL-TRAP220-aa1290-1567

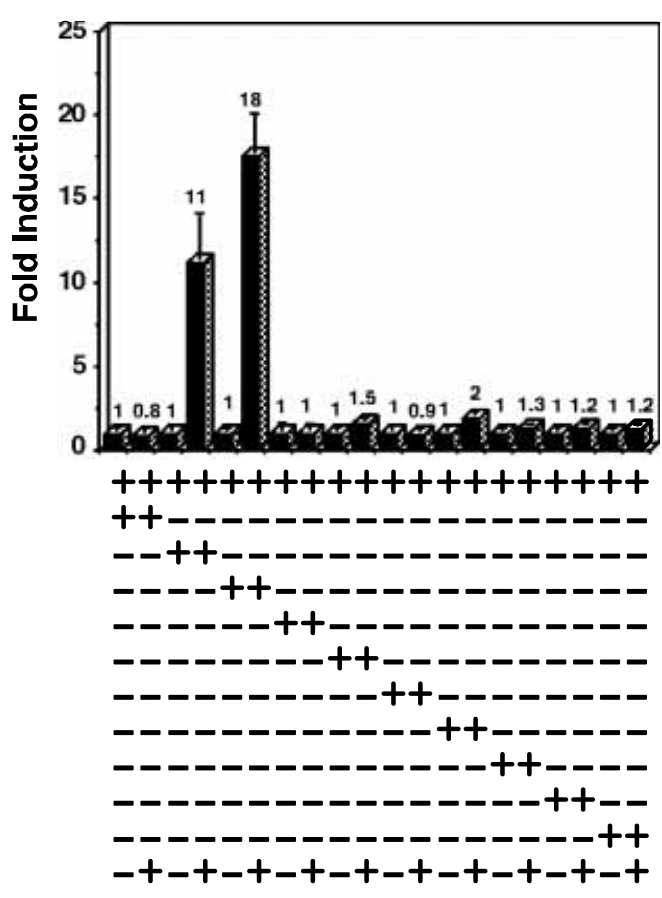

G5E1b-LUC

GAL4-DBD

GAL-TRAP220-aa1-1000

GAL-TRAP220-aa1-800

GAL-TRAP220-aa800-1567

GAL-TRAP220-aa1-330

GAL-TRAP220-aa330-660

GAL-TRAP220-aa660-970

GAL-TRAP220-aa970-1300

GAL-TRAP220-aa330-1567

GAL-TRAP220-aa1290-1567 6-MP( $50 \mu \mathrm{M})$

Figure 2 The region between amino acids 1-800 of TRAP220 mediates activation by 6-MP. (A) Diagrammatic representation of SV40-GAL-TRAP220 chimeric constructs. (B) GAL-TRAP220-aa1-1000, GAL-TRAP220-aa1-800, GAL-TRAP220-aa800-1567, GAL-TRAP220-aa1-330, GAL-TRAP220-aa330-660, GAL-TRAP220-aa660-970, GAL-TRAP220-aa970-1300, GAL-TRAP220-aa330-1567 and GAL-TRAP220aa1290-1567 $(0 \cdot 16 \mu \mathrm{g})$ were cotransfected with the reporter plasmid G5E1b-LUC $(0.83 \mu \mathrm{g})$ into $\mathrm{C} 2 \mathrm{C} 12$ proliferating myoblasts. Fold activation is expressed relative to luciferase activity obtained after cotransfection of the GAL4 DBD alone in the absence of 6-MP arbitrarily set at 1 . The mean luciferase fold activation/induction and S.D. values (bars) were derived from a minimum of 2-3 independent triplicate experiments.

system we observed, as before (Figs $1 \mathrm{~B}$ and $1 \mathrm{C}$ ) the region between amino acids $1-1000$ of TRAP220 retained the potential to be activated significantly by 6-MP. Further delimiting of TRAP220 demonstrated that the region activated by $6-\mathrm{MP}$ was between amino acids $1-800$, which was activated 18- fold over the TRAP220-mediated transcription of the reporter gene in the absence of 6-MP (Fig. 2B). The importance of amino acids $1-800$ of TRAP220 in mediating 6-MP activation was reinforced by the observation that domains downstream of amino acids 800 were not activated by 6-MP. For example, deletions containing amino acid regions 660-970, 970-1300, 300-1567 and 1290-1567 of TRAP220 did not mediate 6-MP 


\section{G5E1b-LUC \\ GAL4-DBD}

GAL-TRAP220-aa1-800

GAL-TRAP220-S756A/S757A- - - - + + -

GAL-TRAP220-S796A/S797A- - - - - - + +

6-MP $(100 \mu \mathrm{M}) \quad-+-+-++++$

Figure 3 The characterized protein kinase A and C sites in TRAP220 are not involved in 6-MP-mediated modulation of TRAP220 activity. (A) Schematic diagram of the TRAP220 showing PKA and PKC sites and the LXXLL signature motifs (NR1 and NR2). (B) GAL-TRAP220-aa1-800, GAL-TRAP220-S656A/S657A,

GAL-TRAP220-S756A/S757A and GAL-TRAP220-S796A/S797A chimeras $(0 \cdot 16 \mu \mathrm{g})$

were cotransfected with the reporter plasmid G5E1b-LUC $(0.83 \mu \mathrm{g})$ into C2C12 proliferating myoblasts. Fold activation is expressed relative to luciferase activity obtained after cotransfection of the GAL4 DBD alone in the absence of 6-MP arbitrarily set at 1 . The mean luciferase fold activation and S.D. values (bars) were derived from a minimum of 2-3 independent triplicate experiments.

activation. Furthermore, additional delimitation of the first 800 amino acids into smaller segments spanning amino acids, 1-300 and 300-660 TRAP220 were not activated by $6-\mathrm{MP}$ (Figs $2 \mathrm{~A}$ and $\mathrm{B}$ ).

The characterized protein kinase $A$ and $C$ sites in TRAP220 are not involved in 6-MP mediated modulation of TRAP220 activity

It has been proposed that phosphorylation regulates p300/CBP and SRC-1 coactivator function (Janknecht \& Nordheim 1996, Rowan et al. 2000, See et al. 2001, Gusterson et al. 2002, McKenna \& O’Malley 2002a). Moreover, in vitro and in vivo approaches identified that TRAP220 is phosphorylated, the major phosphorylation sites were subsequently identified to be protein kinase $\mathrm{A}(\mathrm{PKA}), \mathrm{C}(\mathrm{PKC})$ and mitogen-activated protein kinase (MAPK) sites. Furthermore, the effect of MAPK activation on TRAP220-mediated PPAR $\gamma$ transcription suggested that this kinase signal pathway positively influences TRAP220 function (Misra et al. 2002).

The region of TRAP220 (amino acids 1-800) that mediates 6-MP activation contains the defined PKC and PKA phosphorylation sites (Fig. 3A). We mutated these PKA and PKC sites within TRAP220 and investigated the effect of the mutations on 6-MP-mediated activation of TRAP220. We changed the two critical serines in each of the three defined kinase motifs to alanines. We observed that the mutants GAL-TRAP220-S656A/S657A, GAL-TRAP220-S756A/S757A and GAL-TRAP220S796A/S797A did not compromise the ability of 6-MP to modulate the activity of TRAP220 (Fig. 3B). 


\section{TRAP220 expression stimulates the activity of NOR-1}

Our previous studies had demonstrated the direct in vitro binding of SRC-2 and TRAP220 to Nur77 and NOR-1. Furthermore, we demonstrated that SRG-2 modulated the activity of Nur77 and NOR-1 (Wansa et al. 2003). Activation of gene expression by the classical nuclear hormone receptors is dependent on the recruitment of the SRCs that recruit a number of cofactors in a sequential manner that possess intrinsic histone acetyltransferase (HAT) activity, and precipitate the assembly of a higher order structure that includes the TRAP/ DRIP protein complex that regulates localised nucleosome structure (Glass \& Rosenfeld 2000). The key member of the TRAP/DRIP complex is the TRAP220/ DRIP205 subunit that has also been shown to interact with many NRs, such as vitamin D receptor (VDR), thyroid receptor (TR), androgen receptor (AR), estrogen receptor (ER), glucocorticoid receptor (GR) and peroxisome proliferator activated-receptor (PPAR $\gamma)$ (Zhu et al. 1997, Hittelman et al. 1999, Sharma \& Fondell 2002, Burakov et al. 2000, Ren et al. 2000, Wang et al. 2002, Acevedo \& Kraus 2003).

Hence, we wished to investigate whether TRAP220 modulated the activity of NOR-1 in the GAL4 hybrid system. In these assays the activity of NOR-1 is independent of its binding to its cognate binding motifs. If TRAP220 regulates the transcriptional activity of NOR-1, then the potential of the GAL4-NOR-1-FL fusions to trans-activate gene expression should be increased in this assay (Fig. 4A). C2C12 cells were cotransfected with GAL-NOR-1-FL and the G5E1bLUC reporter in the presence and absence of an SRC-2 or TRAP220 expression vector (Fig. 4B). Transfection of GAL-NOR-1-FL efficiently induced transcription relative to the GAL4 DBD, this level of activity was stimulated by the addition of SRC-2 by $\sim 3$-fold (Fig. 4B) as we had previously shown (Wansa et al. 2003). Furthermore, we observed that NOR-1 activity was also stimulated in the presence of TRAP220 by $\sim 3$ fold, this suggested that NOR-1-mediated transcriptional activation is coactivated by TRAP220.

Subsequently, we examined whether TRAP220 potentiates NOR-1-mediated activation of a native NR4A response element. We utilized a heterologous reporter gene that contains native NOR-1 response elements i.e. the NurRE-5 POMG-tk-LUG reporter contains five copies of the naturally occurring NR4A response element (TGATATTTACGTCCAAATGCGA) from the pro-opiomelanocortin (POMC) gene, (Fig. 4C). This native response element is responsive to physiological stimuli, binds NR4A dimers and efficaciously responds to NR4A mediated transactivation (Maira et al. 1999). C2C12 muscle cells were cotransfected with the reporter plasmid NurRE-5 POMC-tk-LUG and the NOR-1 expression vector. We observed efficient NOR-1-dependent transactivation of the NurRE-5 POMC reporter by $\sim 60$-fold (Fig. 4D) as previously reported. Moreover, increasing concentrations of TRAP220 expression plasmid potentiated NOR-1mediated activation of the native response element by 4-9-fold, consistent with the GAL4 hybrid assay (Fig. 4A). Higher concentrations of TRAP220 resulted in squelching of NOR-1-mediated transcription (data not shown).

In addition, 6-MP induced NOR-1-mediated transactivation of the NurREPOMC reporter by $>5$-fold, as previously reported (Wansa et al. 2003). Interestingly, TRAP220 expression did not further potentiate the induction of NOR-mediated transactivation by $6-\mathrm{MP}$, however, the absolute level of NOR-1 mediated reporter gene activation was certainly increased in the presence of TRAP220 and 6-MP (Fig. 4D). These experiments indicate NOR-1-mediated transcriptional activation is potentiated by TRAP220.

\section{NOR-1 and Nur77 interact with TRAP220 in an AF-1-dependent manner in a cellular context: amino acids 1-800 of TRAP220 are necessary for nuclear receptor recruitment}

Our previous studies demonstrated that NOR-1 could recruit TRAP220 in vitro. To investigate whether NOR-1 and Nur77 could interact with TRAP220 in a cellular context in vivo we utilised the mammalian two-hybrid assay. In these experiments the yeast GAL4 DBD domain is fused to TRAP220 and expressed in transfected JEG-3 cells with NOR-1 or Nur77 linked to the transactivation domain (AD) of the herpes simplex virus, VP16. Transactivation of a GAL4-dependent reporter gene (G5E1 bLUG) is only achieved when the coexpressed proteins interact physically (Fig. 5A).

JEG-3 cells (and not the C2C12 muscle cells) were utilized for the mammalian two-hybrid assays, because the activity of NOR-1, Nur77 and TRAP220 is high in C2C12, COS-1 and 293 cells (data not shown) (Castro et al. 1999, Wansa et al. 2002, 2003). Furthermore, Castro et al. (1999) reported that the NR4A activity in this cell line is very weak, consequently background activity is low, thus enabling in vivo interactions to be observed (and increasing the sensitivity of the assay). This feature of JEG-3 cells was previously exploited in the mammalian two-hybrid assays involving this subgroup of receptors (Perlmann \& Jansson 1995).

We observed that coexpression of VP16-NOR-1 and VP16-Nur77 effectively and significantly trans-activated GAL-TRAP220 by $\sim 5$ - and 15-fold, respectively (Fig. 5B), in concordance with our GST-pulldown studies (Wansa et al. 2002, 2003).

To determine the regions of NOR-1 and Nur77 that mediated the in vivo interactions with TRAP220, we 
performed mammalian two-hybrid experiments in which the $\mathrm{N}$ and C-terminal regions of NOR-1 and Nur77 (for example, NOR-1-AB, NOR-1-DE, Nur77-AB or Nur77-DE) were linked to the transactivation domain of the herpes simplex virus, VP16. We observed that VP16-NOR-1-AB and VP16-Nur77-AB
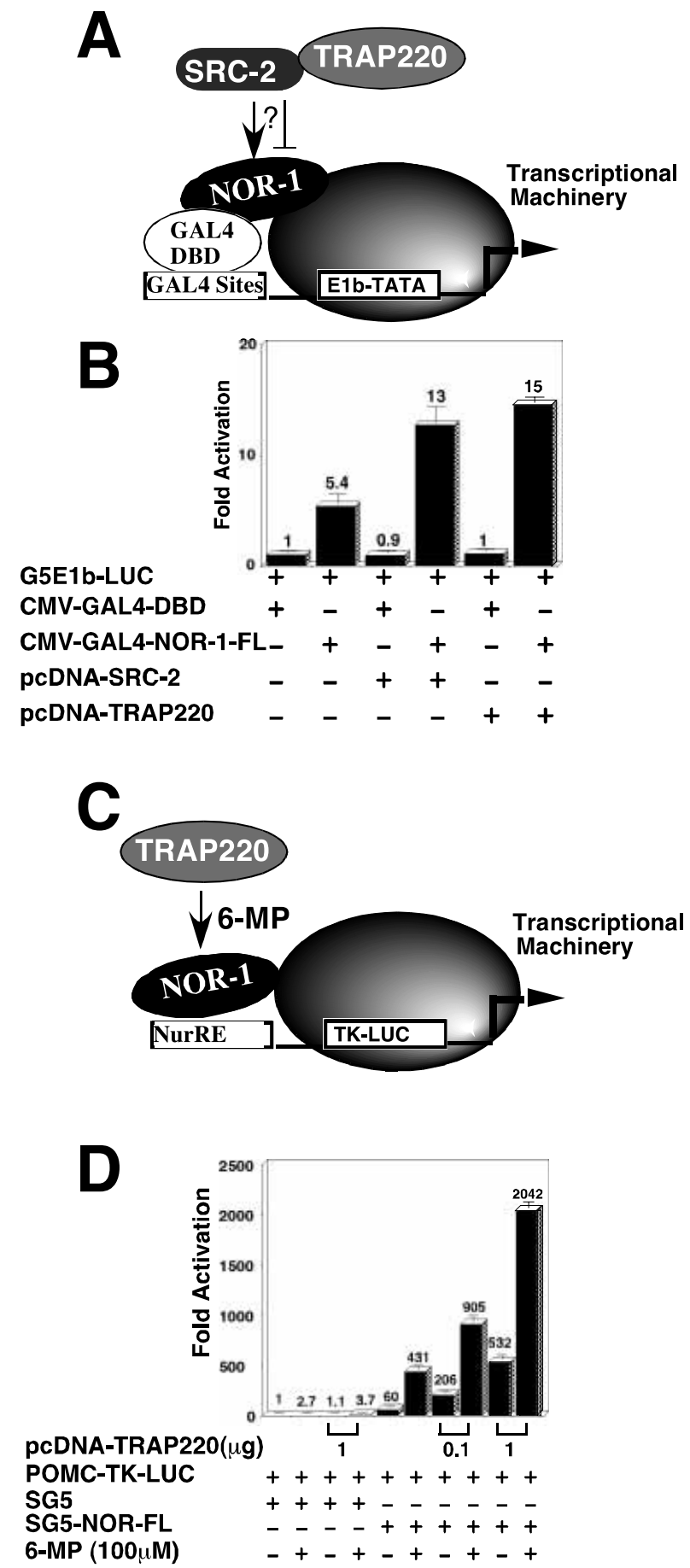

effectively and significantly transactivated GALTRAP220 activity by $\sim 5$-fold. In contrast, the C-terminal DE regions of these receptors, in an atypical manner, failed to complement the activity of TRAP220 (Figs 5C and 5D). This is consistent with the AF-1-dependent nature of NOR-1 activity.

However, we did not observe increased NOR-1mediated recruitment of TRAP220 in the presence of 6-MP (Fig. 6A). To further determine whether 6-MP could potentiate TRAP220-induced NOR-1-mediated transcription we utilized and further exploited the GAL4 hybrid assay (Fig. 6B). As demonstrated in Figure $4 \mathrm{~A}$, NOR-1 activity was stimulated in the presence of TRAP220, in this reverse assay TRAP220 activity was increased by NOR-1 co-expression by $\sim 3$-fold (Fig. 6C). As observed initially, TRAP220 activity was stimulated by $6-\mathrm{MP}$ (Figs $1 \mathrm{~B}$ and $6 \mathrm{C}$ ), however NOR-1 expression did not increase the inducibility of TRAP220 activity by 6-MP. Although the absolute level of activation (relative to the GAL4 DBD) was clearly increased.

We progressed to further utilize this assay to delimit the region of TRAP220 that mediates interaction with NOR-1 and Nur77 employing the mammalian twohybrid assay. Interestingly, the region between amino acids 1-800 of TRAP220, which mediates transcriptional activation by $6-\mathrm{MP}$, is also necessary to support the cellular interaction with NOR-1 and Nur77. We observed that VP16-NOR-1-FL and VP16-Nur77-FL significantly transactivated GAL-TRAP220-aal-800 activity by $\sim 3$-fold and $\sim 11$-fold, respectively (Fig. 7). The regions of TRAP220 that were previously shown to not be modulated by 6-MP (Fig. 2B) did not interact with NOR-1 and Nur77, thus demonstrating the importance of the region between amino acids 1-800 of

Figure 4 TRAP220 potentiates the activity of NOR-1 (A) A diagrammatic representation of the GAL4 hybrid assay is shown. This assay was used to determine the effect of SRC-2/GRIP-1 TRAP220 expression on NOR-1-mediated transactivation of gene expression. pCMV-GAL-NOR-1-FL $(0.16 \mu \mathrm{g})$ was co-transfected with the reporter plasmid G5E1b-LUC $(1 \mu \mathrm{g})$ into C2C12 proliferating myoblasts in the presence and absence of the co-transfected expression plasmid encoding pcDNA-SRC-2 or pcDNA-TRAP220 $(2 \mu \mathrm{g}$ per 3 wells). Fold activation is expressed relative to luciferase activity obtained after cotransfection of the pCMVGAL4 DBD alone arbitrarily set at 1 . The mean luciferase fold activation and S.D. values (bars) were derived from a minimum of 2 independent triplicate experiments. (C) A diagrammatic representation of the reporter gene assay. (D) SG5-NOR-1-FL $(0.16 \mu \mathrm{g})$ pcDNA-TRAP220 $(0.1,0.3$ and $1 \mu \mathrm{g}$ per 3 wells) were co-transfected into $\mathrm{C} 2 \mathrm{C} 12$ proliferating myoblasts together with the reporter gene NurRE-5-tk-Luc in the presence and absence of $100 \mu \mathrm{M} 6$-MP. Fold activation is expressed relative to luciferase activity obtained after cotransfection of pSG5 alone, arbitrarily set at 1 . The mean luciferase fold activation values and standard deviations (bars) were derived from a minimum of 2-3 independent triplicate experiments. 
\begin{tabular}{lll}
$A$ & GAL4 DBD & TRAP220/DRIP205 \\
\hline
\end{tabular}
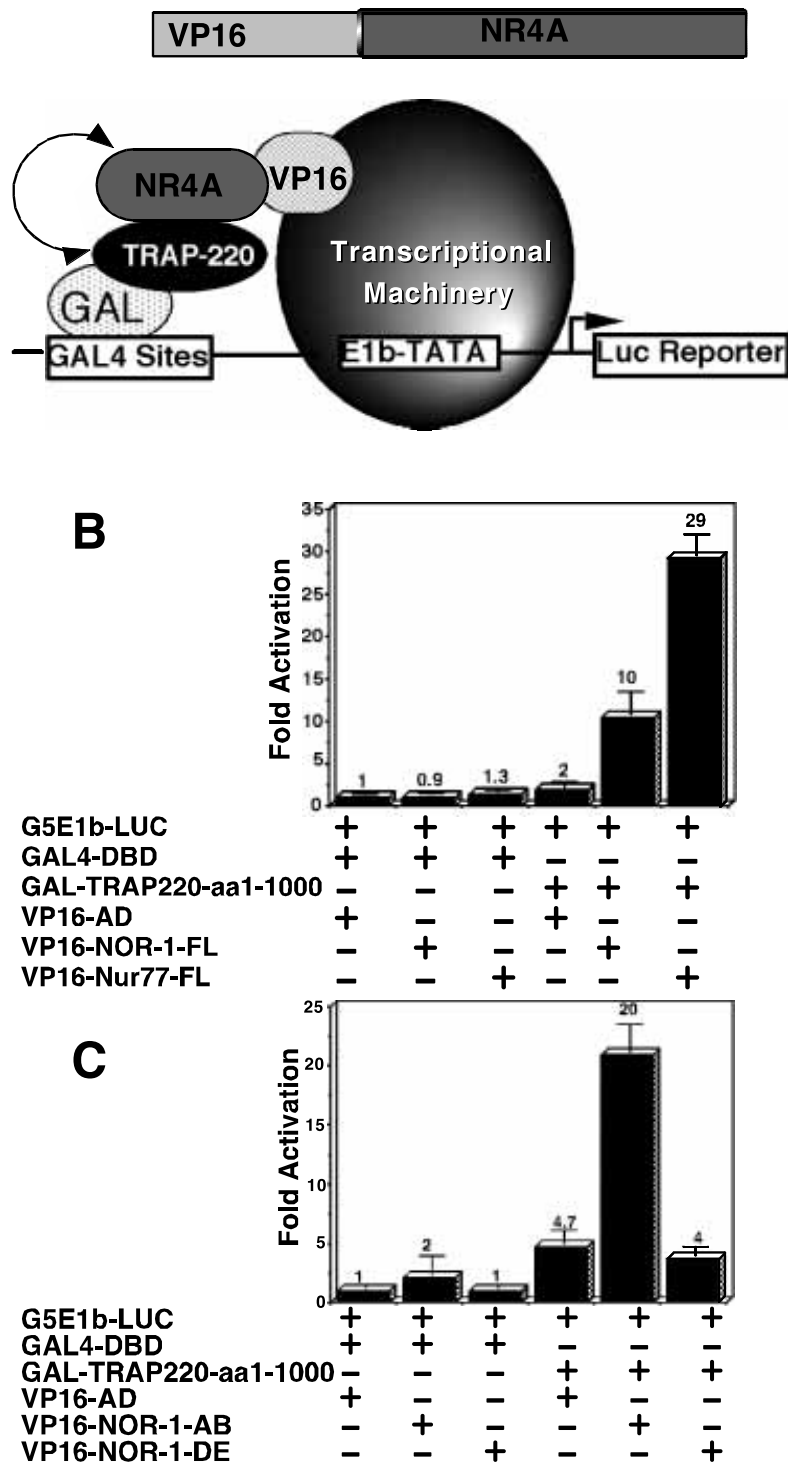

D

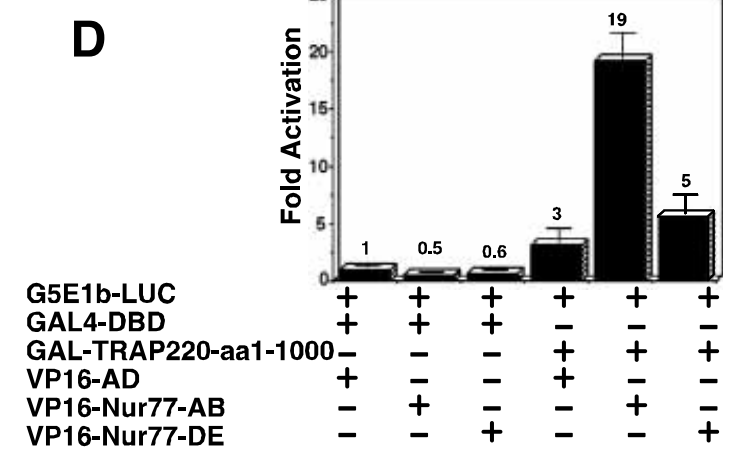

TRAP220 for modulation by 6-MP, as well as mediating interactions with NOR-1 and Nur-77 (Fig. 7).

These mammalian two-hybrid experiments clearly demonstrate that NOR-1 and Nur77 significantly interact with TRAP220 in a cellular context in an $\mathrm{AF}-1$ / AB region-dependent manner. This is concordant with the in vitro GST-pulldown assays that showed that the AB regions of NOR-1 and Nur77 mediate coactivator recruitment, and that the LBD interacts poorly with coactivators (Wansa et al. 2002, 2003). Moreover, we demonstrated that a TRAP220 deletion mutant containing only the NR-interacting regions (LXXLL motifs) did not interact with NOR-1 and Nur77. This is in contrast to other NRs, where coactivators interact with NRs namely through key interactions with residues in the LBD domain that form part of a charged clamp that accommodates the coactivator LXXLL $\alpha$-helix motifs within a hydrophobic cleft in the LBD, conversely NOR-1 and Nur77 were shown to have unusually hydrophilic coactivator binding interfaces, thus accounting for the inability of NOR-1 and Nur77 LBDs to efficiently recruit TRAP220 (data no shown).

\section{Discussion}

In this study we have provided evidence that the purine anti-metabolite 6-MP, which has anti-proliferative, anti-cancer and anti-inflammatory properties, stimulated the activity of the coactivator TRAP220. The 6-MPmediated activation of NOR-1 and TRAP220 is observed at an EC50 of $33-50 \mu \mathrm{M}$, and increases in a dose-dependent manner. We could not obtain saturating concentrations of 6-MP on NOR-1 and TRAP220 activation because at $6-\mathrm{MP}$ concentrations of $>100 \mu \mathrm{M}$ we observed a dose-dependent increase of $>2$-fold in the activity of the basal GAL4 DBD. This is consistent with the observations from Ordentlich and colleagues (Ordentlich et al. 2003). The range of 6-MP concentrations required for inhibition of purine biosynthesis varies greatly from cell to cell, with sensitive cell lines

Figure 5 TRAP220 directly interact with the AF-1 domain of NOR-1 and Nur77 in vivo. (A) Diagrammatic representation of the mammalian two-hybrid assay used to determine the interaction and cooperativity of TRAP220, NOR-1 and Nur77 in a cellular context. (B) GAL-TRAP220-aa1-1000 (0.33 $\mu \mathrm{g})$, VP16-NOR-1-FL, VP16-NOR-1-AB, VP16-NOR-1-DE,

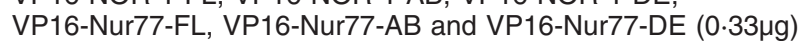
were cotransfected with the reporter plasmid G5E1b-LUC $(1 \mu \mathrm{g})$ in JEG3 cells. Fold activation is expressed relative to luciferase activity obtained after cotransfection of the SV40-GAL4 DBD and the SV40-VP16AD plasmids alone, arbitrarily set at 1 . The mean luciferase fold activation and S.D. values (bars) were derived from a minimum of 2-3 independent triplicate experiments. 
such as human lymphoblastic Molt F4 requiring $0 \cdot 5-10 \mu \mathrm{M}$ and some cell lines being resistant at concentrations above $100 \mu \mathrm{M}$ (Ordentlich et al. 2003). Therefore, most biological effects of 6-MP observed to date occur in the micro molar range, and activation of NOR-1 and TRAP220 is concordant with the clinical utilization of this drug.

Transcriptional activation of NRs involves the stepwise recruitment and binding of coactivators to target gene promoters (McKenna \& O’Malley 2002b). Initial recruitment of SRCs, p300/CBP, PGAF and CARM1 by ligand-activated NRs leads to subsequent

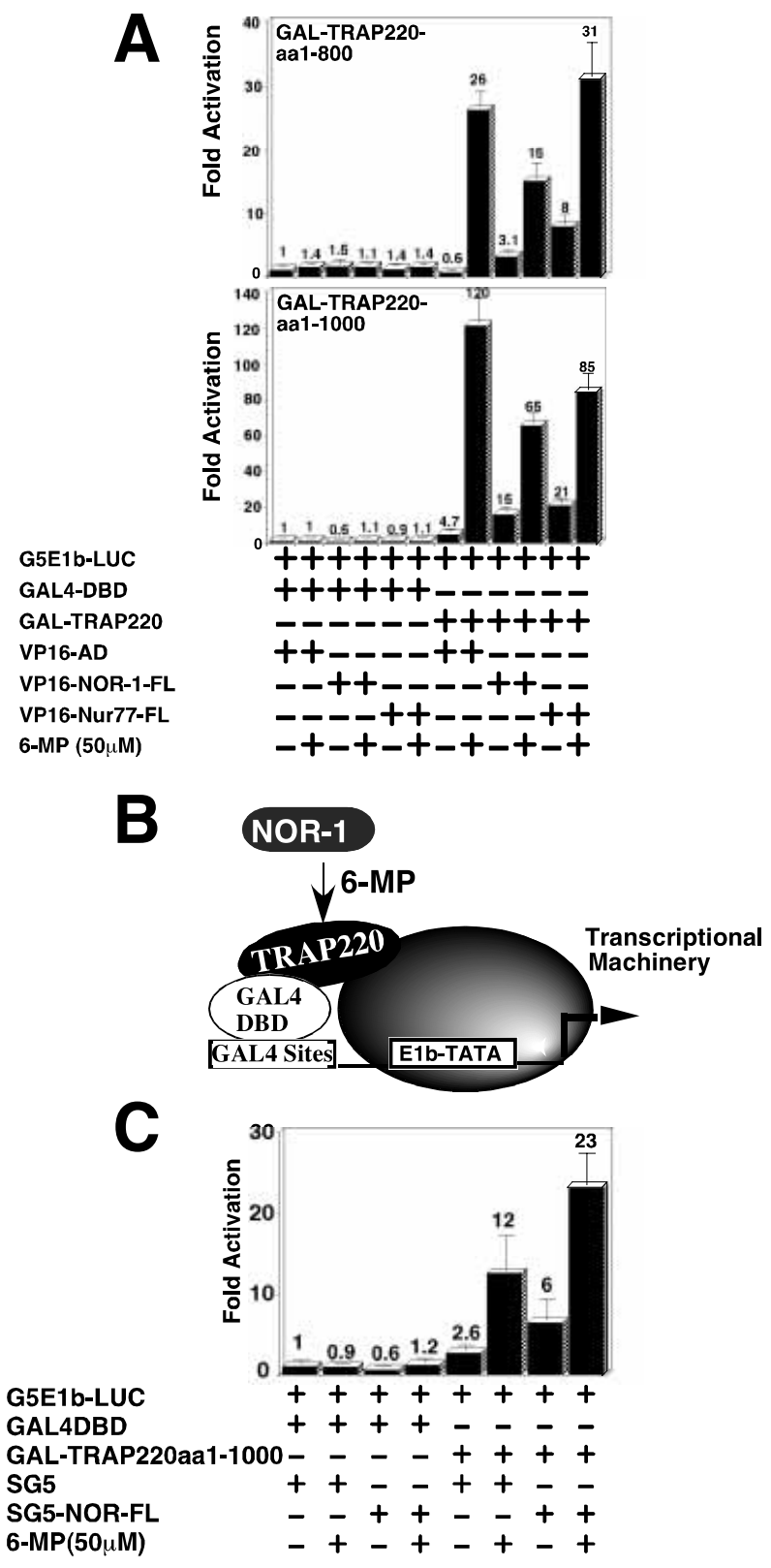

Journal of Molecular Endocrinology (2005) 34, 835-848 conscription of the TRAP/DRIP complex (McKenna \& O'Malley 2002a). The single TRAP subunit, TRAP220, directly contacts TR, VDR, GR and ER in a ligand-dependent manner and is thought to anchor the TRAP/DRIP complex to DNA-bound NRs. We demonstrated that TRAP220 potentiates NOR-1mediated transactivation. In addition, NOR-1 and Nur77 interact with TRAP220 in an AF-1-dependent manner in a cellular context. Interestingly TRAP220 expression does not increase the extent of inducibility by 6-MP. However, the absolute level of NOR-1-mediated activation is increased, suggesting additive rather than synergistic outcomes of 6-MP-mediated activation of NOR-1 and TRAP220.

TRAP220 is a member of a multi subunit complex, composed of at least 16 different polypeptides, ranging in size from $\sim 15$ to $240 \mathrm{kDa}$ (Malik \& Roeder 2000, Rachez \& Freedman 2001). It has been shown that over expression of TRAP170 and TRAP100, members of the TRAP-complex also enhance ligand-dependent transcription by AR in cultured cells in a similar manner to TRAP220, indicating that other members of the TRAP-mediator complex are involved in binding and subsequent targeting of the TRAP-mediator complex to AR (Wang et al. 2002). Furthermore, TRAP170 interacts with the AF-1 domain of GR. It has been demonstrated that TRAP220 interacts with the GR ligand binding domain in a hormone-dependent manner and facilitates GR transactivation in concert with TRAP170/DRIP150 (Hittelman et al. 1999). Whether other members of the TRAP-complex may be required for coactivation of NOR-1-mediated transcription in response to 6-MP needs to be further investigated.

The NR4A1-3 subfamily has been shown to be involved in the regulation of apoptosis in prostate, lung, gastric, breast and colon cancer cells $(\mathrm{Li}$ et al. 1998, Kang et al. 2000, Li et al. 2000, Ohkubo et al. 2000, Liu et al. 2002, Wu et al. 2002, Zhang 2002). Nur77 induces thymocyte apoptosis in a AF-1-dependent manner in

Figure 6 6-MP does not potentiate stimulation by TRAP220 in NOR-1-mediated transcription. GAL-TRAP220-aa1-1000, GAL-TRAP220-aa1-800 (0.33 $\mu \mathrm{g})$, VP16-NOR-1-FL and VP16-Nur77-FL $(0.33 \mu \mathrm{g})$ were cotransfected with the reporter plasmid G5E1b-LUC $(1 \mu \mathrm{g})$ in JEG-3 cells. Fold activation is expressed relative to luciferase activity obtained after cotransfection of the SV40-GAL4 DBD and the SV40-VP16AD plasmids alone in the absence of 6-MP arbitrarily set at 1. (B) A diagrammatic representation of the GAL4 hybrid assay is

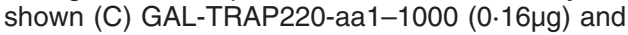
SG5-NOR-1-FL (2 $\mu \mathrm{g}$ per 3 wells) were co-transfected into C2C12 proliferating myoblasts together with the reporter gene G5E1b-LUC $(1 \mu \mathrm{g})$ in the presence and absence of $50 \mu \mathrm{M}$ of 6-MP. Fold activation is expressed relative to luciferase activity obtained after cotransfection of the GAL4 DBD and SG5 alone in the absence of 6-MP, arbitrarily set at 1 . The mean luciferase fold activation and S.D. values (bars) were derived from a minimum of 2-3 independent triplicate experiments. 
G5E1b-LUC

GAL4-DBD

GAL-TRAP220-aa1-1000

GAL-TRAP220-aa1-800

GAL-TRAP220-aa1-330

GAL-TRAP220-aa 330-660

GAL-TRAP220-aa 660-970

GAL-TRAP220-aa 970-1300

GAL-TRAP220-aa 330-1547

VP16-AD

VP16-NOR-1-FL VP16-Nur77-FL

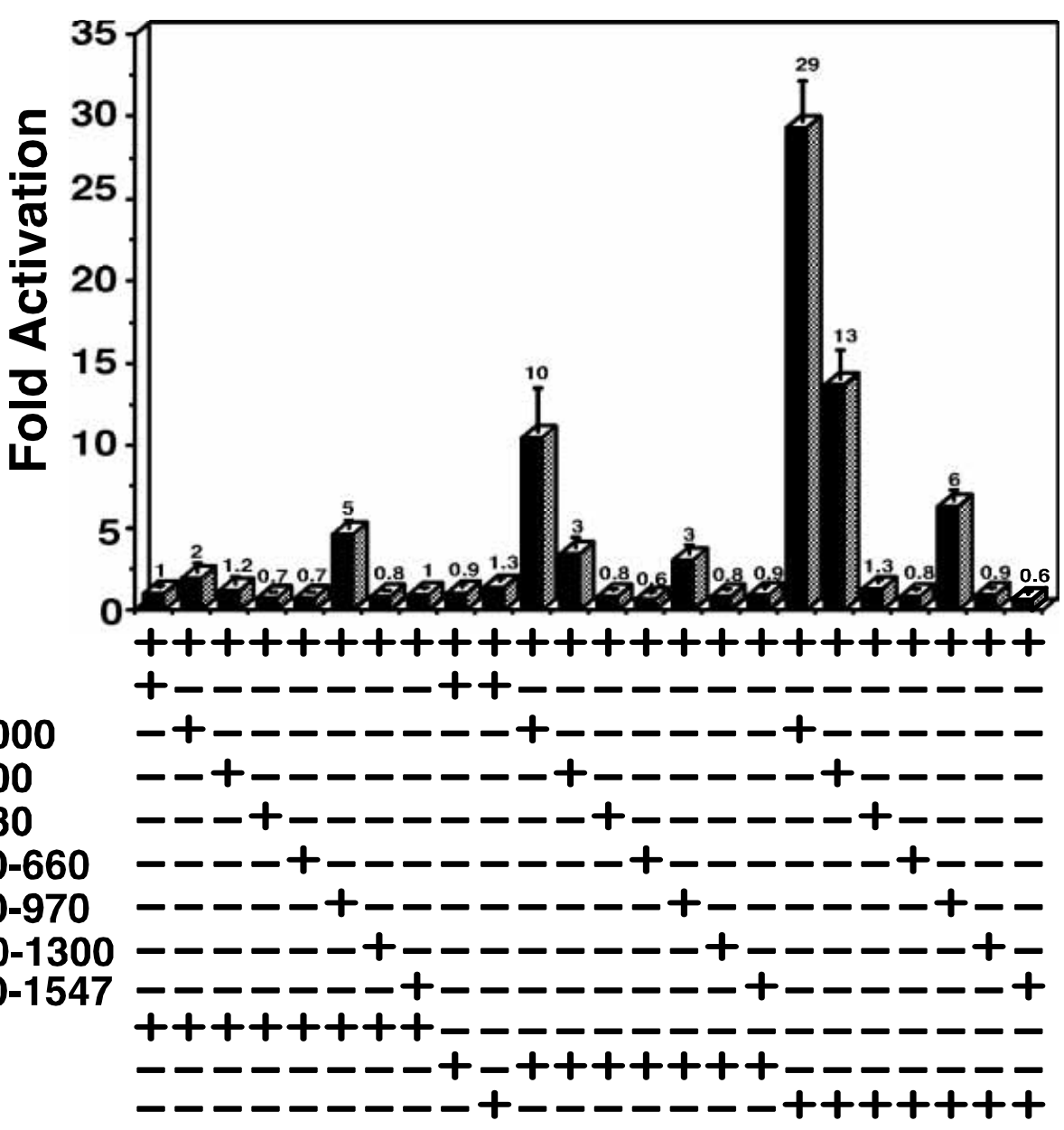

Figure 7 Amino acids 1-800 of TRAP220 are necessary for interaction with NOR-1 and Nur77. GAL-TRAP220-aa1-1000, GAL-TRAP220-aa1-800, GAL-TRAP220-aa1-330, GAL-TRAP220-aa330-660, GAL-TRAP220-aa660-970,

GAL-TRAP220-aa970-1300 and GAL-TRAP220-aa330-1567 (0.16 $\mu$ g) were cotransfected with the reporter plasmid G5E1b-LUC $(0.83 \mu \mathrm{g})$ into JEG3 cells. Fold activation is expressed relative to luciferase activity obtained after cotransfection of the SV40 GAL4 DBD and the SV40-VP16AD plasmids alone, arbitrarily set at 1. The mean luciferase fold activation and S.D. values (bars) were derived from a minimum of 2-3 independent triplicate experiments.

transgenic mice (Kuang et al. 1999). TRAP220 has also been shown to regulate apoptosis through direct regulation of the tumour suppressor p53 (Frade et al. 2002) Interestingly, 6-MP targets the $\mathrm{AB}$ region of the NR4A1-3 subfamily and regulates the receptors' activity, furthermore TRAP220 interacts with the AB region of NOR-1 and Nur77 and stimulates NOR-1mediated transcription. Whereas many of the steps involved in 6-MP-mediated cytotoxicity have been elucidated, it is possible that these effects can be enhanced or suppressed by transcriptional regulation of the NR4A1-3 subfamily.

6-MP is metabolized into the active derivative, 6-thio-inosine-mono-phosphate (6 TIMP), by hypoxanthine-guanine phosphoribosyltransferase (HGPRT), a key enzyme involved in the purine salvage pathway. The 6-thio-IMP can be metabolized into 6 thioguanosine 5' monophosphate, which is then incorporated into DNA and RNA as 6-thio-guanosine triphosphate (6-thio-GTP, 6-TGN) resulting in eventual cytotoxicity and cell death (Cara et al. 2004). Incorporation of 6-TGNs into nucleic acids is considered the main mechanism of 6-MP cytotoxicity. 6-TIMP can be methylated by thiopurine methyltransferase (TPMT) to methyl thioinosine monophosphate (methyl-TIMP), a potent inhibitor of de novo purine biosynthesis which depletes the intracellular ATP pools (Cara et al. 2004). Most relevant to the observation presented in this study is the finding that 6-methyl-mercaptopurine riboside and 6-TGN are specific and effective inhibitors of protein kinase $\mathrm{N}$, which has been implicated in nerve growth factor signalling (Volonte \& Greene 1992, 
Volonte et al. 1993). 6-methy-mecaptopurine riboside can also regulate tyrosine kinase signalling in angiogenesis (Presta et al. 1999). Furthermore, it has been shown that azathioprine and its metabolite 6-MP induced apoptosis of T cells in patients with Crohn's disease and control patients. Apoptosis induction required costimulation with CD28 and was mediated by a specific blockade of Racl activation through binding 6-TGN to Racl instead of GTP. The activation of Racl target genes such as mitogen-activated protein kinase/ extracellular signal regulated kinase (MEK), NF-kappaB and $\mathrm{bcl-x}(\mathrm{L})$ was suppressed by azathioprine, leading to a mitochondrial pathway of apoptosis (Tiede et al. 2003).

The precedent set by these findings suggests that 6-MP may also regulate as yet unidentified activities in the cell that may specifically influence TRAP220 activity. Indeed, stimulation of CBP transcriptional coactivation by MAPK (Janknecht \& Nordheim 1996, Liu et al. 1998), of p300-mediated transcription by mitogen-activated/extracellular response kinase kinase (MEKK1) (See et al. 2001, Gusterson et al. 2002), and SRC-1 function by ERK1 and ERK2 (Rowan et al. 2000) points to phosphorylation as a positive regulatory modification in coactivator activity. Furthermore, $\mathrm{Ca}^{2+} /$ Calmodulin-dependent protein kinase IV (CaMKIV) enhances Nur77 transactivation in cotransfections in synergy with the CaMKIV responsive coactivator activating signal cointegrator-2 (ASC-2) (Sohn et al. 2001). Interestingly, TRAP220 contains PKC, PKA and MAPK sites that were shown to be phosphorylated by these kinases. The effect of MAPK activation on TRAP220 mediated PPAR $\gamma$ transcription suggests that this kinase signalling pathway positively influences TRAP220 function (Misra et al. 2002). Interestingly, the region of TRAP220 (aal-800) that mediates transactivation in response to 6-MP contains $\mathrm{PKC}$ and $\mathrm{PKA}$ phosphorylation sites, however mutation of these sites did not compromise the ability of 6-MP to activate TRAP220.

Apoptosis represents an effective way to eliminate cancerous cells and a variety of evidence suggests both the NR4A1-3 subfamily of nuclear receptors and TRAP220 to be implicated in cancer and apoptosis $(\mathrm{Li}$ et al. 1998, Zhu et al. 1999, Kang et al. 2000, Li et al. 2000, Ohkubo et al. 2000, Frade et al. 2002, Liu et al. 2002, Wu et al. 2002, Zhang 2002, Wada et al. 2004). Therefore, we speculate that there exists a cell signalling cascade that is sensitive to either levels of purine nucleotides or to regulation by 6-MP and that this pathway induces NR4A1-3 modulation. We suggest that 6-MP could act in concert with cellular signal transduction pathways to modulate NR4A-mediated transcription. In this regard, TRAP220 could serve to integrate the signalling cascade with NR4A-mediated transcription in response to 6-MP. Characterization of these signalling cascades has utility in the design of pharmacological tools for the selective therapeutic regulation of the NR4A subgroup in treatment of Parkinson's disease, atherogenesis, Alzheimer's disease, rheumatoid arthritis and cancer.

\section{References}

Acevedo ML \& Kraus WL 2003 Mediator and p300/CBP-steroid receptor coactivator complexes have distinct roles, but function synergistically, during estrogen receptor alpha-dependent transcription with chromatin templates. Molecular and Cellular Biology 23 335-348.

Arkenbout EK, de Waard V, van Bragt M, van Achterberg TA, Grimbergen JM, Pichon B, Pannekoek H \& de Vries CJ 2002 Protective function of transcription factor TR3 orphan receptor in atherogenesis: decreased lesion formation in carotid artery ligation model in TR3 transgenic mice. Circulation 106 1530-1535.

Backman C, Perlmann T, Wallen A, Hoffer BJ \& Morales M 1999 A selective group of dopaminergic neurons express Nurrl in the adult mouse brain. Brain Research 851 125-132.

Baker KD, Shewchuk LM, Kozlova T, Makishima M, Hassell A, Wisely B, Caravella JA, Lambert MH, Reinking JL, Krause H $e t$ al. 2003 The Drosophila orphan nuclear receptor DHR38 mediates an atypical ecdysteroid signaling pathway. Cell $\mathbf{1 1 3}$ 731-742.

Borghaei RC, Sinai RS, Mochan E \& Pease EA 1998 Induction of mitogen-inducible nuclear orphan receptor by interleukin 1 in human synovial and gingival fibroblasts. Biochemical and biophysical research communications $\mathbf{2 5 1} 334-338$.

Buervenich S, Carmine A, Arvidsson M, Xiang F, Zhang Z, Sydow O, Jonsson EG, Sedvall GG, Leonard S, Ross RG et al. 2000 NURRl mutations in cases of schizophrenia and manic-depressive disorder. American Fournal of Medical Genetics 96 808-813.

Burakov D, Wong CW, Rachez C, Cheskis BJ \& Freedman LP 2000 Functional interactions between the estrogen receptor and DRIP205, a subunit of the heteromeric DRIP coactivator complex. Fournal of Biological Chemistry 275 20928-20934.

Cara CJ, Pena AS, Sans M, Rodrigo L, Guerrero-Esteo M, Hinojosa J, Garcia-Paredes J \& Guijarro LG 2004 Reviewing the mechanism of action of thiopurine drugs: towards a new paradigm in clinical practice. Medical science monitor $\mathbf{1 0}$ RA247-254.

Casanova J, Helmer E, Selmi-Ruby S, Qi JS, Au-Fliegner M, Desai-Yajnik V, Koudinova N, Yarm F, Raaka BM \& Samuels HH 1994 Functional evidence for ligand-dependent dissociation of thyroid hormone and retinoic acid receptors from an inhibitory cellular factor. Molecular and Cellular Biology 14 5756-5765.

Castro DS, Arvidsson M, Bondesson Bolin M \& Perlmann, T 1999 Activity of the Nurrl carboxyl-terminal domain depends on cell type and integrity of the activation function 2. Fournal of Biological Chemistry 272 37383-37390.

Chawla A, Repa JJ, Evans RM \& Mangelsdorf DJ 2001 Nuclear receptors and lipid physiology: opening the X-files. Science $\mathbf{2 9 4}$ $1866-1870$

Chen SL, Dowhan DH, Hosking BM \& Muscat GE 2000 The steroid receptor coactivator, GRIP-1, is necessary for MEF-2C-dependent gene expression and skeletal muscle differentiation. Genes and Development 14 1209-1228.

Chen SL, Loffler KA, Chen D, Stallcup MR \& Muscat GE 2002 The coactivator associated arginine methyltransferase is necessary for muscle differentiation: CARM1 coactivates myocyte enhancer factor-2. Fournal of Biological Chemistry $2774324-4333$.

Chen YH, Tsai MT, Shaw CK \& Chen CH 2001 Mutation analysis of the human NR4A2 gene, an essential gene for midbrain dopaminergic neurogenesis, in schizophrenic patients. American Journal of Medical Genetics 105 753-757. 
Frade R, Balbo M \& Barel M 2002 RB18A regulates p53-dependent apoptosis. Oncogene 21 861-866.

Glass CK \& Rosenfeld MG 2000 The coregulator exchange in transcriptional functions of nuclear receptors. Genes and Development $14121-141$.

Gronemeyer H \& Laudet V 1995 Transcription factors 3: nuclear receptors. Protein Profile 2 1173-1308.

Gusterson R, Brar B, Faulkes D, Giordano A, Chrivia J \& Latchman D 2002 The transcriptional co-activators CBP and p300 are activated via phenylephrine through the p42/p44 MAPK cascade. Fournal of Biological Chemistry 277 2517-2524.

Harris JM, Lau P, Chen SL \& Muscat GE 2002 Characterization of the retinoid orphan-related receptor-alpha coactivator binding interface: a structural basis for ligand-independent transcription. Molecular Endocrinology 16 998-1012.

Hittelman AB, Burakov D, Iniguez-Lluhi JA, Freedman LP \& Garabedian MJ 1999 Differential regulation of glucocorticoid receptor transcriptional activation via $\mathrm{AF}-1$-associated proteins. Embo fournal 18 5380-5388.

Janknecht R \& Nordheim A 1996 MAP kinase-dependent transcriptional coactivation by Elk-1 and its cofactor CBP. Biochemical and Biophysical Research Communications 228 831-837.

Kang HJ, Song MJ, Choung SY, Kim SJ \& Le MO 2000 Transcriptional induction of Nur77 by indomethacin that results in apoptosis of colon cancer cells. Biological and Pharmaceutical Bulletin 23 815-819.

Kato GJ, Barrett J, Villa-Garcia M \& Dang CV 1990 An amino-terminal c-myc domain required for neoplastic transformation activates transcription. Molecular and Cellular Biology $105914-5920$.

Kim KS, Kim CH, Hwang DY, Seo H, Chung S, Hong SJ, Lim JK, Anderson T \& Isacson O 2003 Orphan nuclear receptor Nurrl directly transactivates the promoter activity of the tyrosine hydroxylase gene in a cell-specific manner. Fournal of Neurochemistry 85 622-634.

Kuang AA, Cado D \& Winoto A 1999 Nur77 transcription activity correlates with its apoptotic function in vivo. European Fournal of Immunology 29 3722-3728.

Labelle Y, Bussieres J, Courjal F \& Goldring MB 1999 The EWS/TEC fusion protein encoded by the $\mathrm{t}(9 ; 22)$ chromosomal translocation in human chondrosarcomas is a highly potent transcriptional activator. Oncogene 18 3303-3308.

Le WD, Xu P, Jankovic J, Jiang H, Appel SH, Smith RG \& Vassilatis DK 2003 Mutations in NR4A2 associated with familial Parkinson disease. Nature Genetics 33 85-89.

Li H, Kolluri SK, Gu J, Dawson MI, Cao X, Hobbs PD, Lin B, Chen G, Lu J, Lin F et al. 2000 Cytochrome C release and apoptosis induced by mitochondrial targeting of nuclear orphan receptor TR3. Science 289 1159-1164.

Li Y, Lin B, Agadir A, Liu R, Dawson MI, Reed JC, Fontana JA, Bost F, Hobbs PD, Zheng Y et al. 1998 Molecular determinants of AHPN (CD437)-induced growth arrest and apoptosis in human lung cancer cell lines. Molecular and Cellular Biology 18 4719-4731.

Lillie JW \& Green MR 1989 Gene transcription: activator's target in sight. Nature 341 279-280.

Liu S, Wu Q, Ye XF, Cai JH, Huang ZW \& Su WJ 2002 Induction of apoptosis by TPA and VP-16 is through translocation of TR3. World Fournal of Gastroenterology 8 446-450.

Liu YZ, Chrivia JC \& Latchman DS 1998 Nerve growth factor up-regulates the transcriptional activity of CBP through activation of the p42/p44(MAPK) cascade. Fournal of Biological Chemistry 273 32400-32407.

McEvoy AN, Bresnihan B, Fitzgerald O \& Murphy EP 2002 Corticotropin-releasing hormone signaling in synovial tissue vascular endothelium is mediated through the cAMP/CREB pathway. Annals of the New York Academy of Sciences 966 119-130.
McKenna NJ \& O’Malley BW 2002a Minireview: nuclear receptor coactivators-an update. Endocrinology 143 2461-2465.

McKenna NJ \& O'Malley BW 2002b Combinatorial control of gene expression by nuclear receptors and coregulators. Cell $\mathbf{1 0 8}$ 465-474.

Maira M, Martens C, Philips A \& Drouin J 1999 Heterodimerization between members of the Nur subfamily of orphan nuclear receptors as a novel mechanism for gene activation Molecular and Cellular Biology 197549 -7557.

Malik S \& Roeder RG 2000 Transcriptional regulation through Mediator-like coactivators in yeast and metazoan cells. Trends in Biochemical Science 25 277-283.

Maltais A, Filion C \& Labelle Y 2002 The AF2 domain of the orphan nuclear receptor TEC is essential for the transcriptional activity of the oncogenic fusion protein EWS/TEG. Cancer Letters 183 87-94.

Misra P, Owuor ED, Li W, Yu S, Qi C, Meyer K, Zhu YJ, Rao MS, Kong AN \& Reddy JK 2002 Phosphorylation of transcriptional coactivator peroxisome proliferator-activated receptor (PPAR)-binding protein (PBP). Stimulation of transcriptional regulation by mitogen-activated protein kinase. Fournal of Biological Chemistry 277 48745-48754.

Monajemi H, Arkenbout EK \& Pannekoek H 2001 Gene expression in atherogenesis. Thrombosis and Haemostasis $86404-412$.

Murphy EP \& Conneely OM 1997 Neuroendocrine regulation of the hypothalamic pituitary adrenal axis by the nurrl/nur77 subfamily of nuclear receptors. Molecular Endocrinology 11 39-47.

Newman SJ, Bond B, Crook B, Darker J, Edge C \& Maycox PR 2000 Neuron-specific localisation of the TR3 death receptor in Alzheimer's disease. Brain Research 857 131-140.

Ohkubo T, Ohkura N, Maruyama K, Sasaki K, Nagasaki K, Hanzawa H, Tsukada T \& Yamaguchi K 2000 Early induction of the orphan nuclear receptor NOR-1 during cell death of the human breast cancer cell line MCF-7. Molecular and Cellular Endocrinology 162 151-156.

Ordentlich P, Yan Y, Zhou S \& Heyman RA 2003 Identification of the antineoplastic agent 6 -mercaptopurine as an activator of the orphan nuclear hormone receptor Nurr 1. Fournal of Biological Chemistry 278 24791-24799.

Perlmann T \& Jansson L 1995 A novel pathway for vitamin A signaling mediated by RXR heterodimerization with NGFI-B and NURR1. Genes and Development 9 769-782.

Presta M, Rusnati M, Belleri M, Morbidelli L, Ziche M \& Ribatti D 1999 Purine analogue 6-methylmercaptopurine riboside inhibits early and late phases of the angiogenesis process. Cancer Research $592417-2424$.

Rachez C \& Freedman LP 2000 Mechanisms of gene regulation by vitamin $\mathrm{D}(3)$ receptor: a network of coactivator interactions. Gene 246 9-21.

Rachez C \& Freedman LP 2001 Mediator complexes and transcription. Current Opinion in Cellular Biology 13 274-280.

Ren Y, Behre E, Ren Z, Zhang J, Wang Q \& Fondell JD 2000 Specific structural motifs determine TRAP220 interactions with nuclear hormone receptors. Molecular and Cellular Biology 20 5433-5446.

Rowan BG, Weigel NL \& O'Malley BW 2000 Phosphorylation of steroid receptor coactivator-1. Identification of the phosphorylation sites and phosphorylation through the mitogen-activated protein kinase pathway. Fournal of Biological Chemistry 275 4475-4483.

Saucedo-Cardenas O, Quintana-Hau JD, Le WD, Smidt MP, Cox JJ, De Mayo F, Burbach JP \& Conneely OM 1998 Nurrl is essential for the induction of the dopaminergic phenotype and the survival of ventral mesencephalic late dopaminergic precursor neurons. PNAS 95 4013-4018.

Schimmel JJ, Crews L, Roffler-Tarlov S \& Chikaraishi DM 1999 $4.5 \mathrm{~kb}$ of the rat tyrosine hydroxylase $5^{\prime}$ flanking sequence directs tissue specific expression during development and contains 
consensus sites for multiple transcription factors. Brain Research and Molecular Brain Research 74 1-14.

See RH, Calvo D, Shi Y, Kawa H, Luke MP \& Yuan Z 2001 Stimulation of p300-mediated transcription by the kinase MEKK1. Fournal of Biological Chemistry 276 16310-16317.

Sharma D \& Fondell JD 2002 Ordered recruitment of histone acetyltransferases and the TRAP/Mediator complex to thyroid hormone-responsive promoters in vivo. PNAS 99 $7934-7939$.

Sohn YC, Kwak E, Na Y, Lee JW \& Lee SK 2001 Silencing mediator of retinoid and thyroid hormone receptors and activating signal cointegrator-2 as transcriptional coregulators of the orphan nuclear receptor Nur77. Fournal of Biological Chemistry $27643734-43739$.

Tiede I, Fritz G, Strand S, Poppe D, Dvorsky R, Strand D, Lehr HA, Wirtz S, Becker C, Atreya R et al. 2003 CD28-dependent Racl activation is the molecular target of azathioprine in primary human CD4+ T lymphocytes. Fournal of Clinical Investigation 111 1133-1145.

Volonte C \& Greene LA 1992 6-Methylmercaptopurine riboside is a potent and selective inhibitor of nerve growth factor-activated protein kinase N. Journal of Neurochemistry 58 700-708.

Volonte C, Ross AH \& Greene LA 1993 Association of a purine-analogue-sensitive protein kinase activity with p75 nerve growth factor receptors. Molecular Biology of the Cell 4 71-78.

Wada O, Oishi H, Takada I, Yanagisawa J, Yano T\& Kato S. 2004 BRCAl function mediates a TRAP/DRIP complex through direct interaction with TRAP220. Oncogene 23 6000-6005.

Wang Q, Sharma D, Ren Y \& Fondell JD 2002 A coregulatory role for the TRAP-mediator complex in androgen receptor-mediated gene expression. Journal of Biological Chemistry $27742852-42858$.

Wang Z, Benoit G, Liu J, Prasad S, Aarnisalo P, Liu X, Xu H, Walker NP \& Perlmann T 2003 Structure and function of Nurr 1 identifies a class of ligand-independent nuclear receptors. Nature $423555-560$.

Wansa KD, Harris JM \& Muscat GE 2002 The activation function-1 domain of Nur77/NR4A1 mediates trans-activation, cell specificity, and coactivator recruitment. Fournal of Biological Chemistry $27733001-33011$.

Wansa KD, Harris JM, Yan G, Ordentlich P \& Muscat GE 2003 The AF-1 domain of the orphan nuclear receptor NOR-1 mediates trans-activation, coactivator recruitment, and activation by the purine anti-metabolite 6-mercaptopurine. Fournal of Biological Chemistry $27824776-24790$.

Willy PJ, Umesono K, Ong ES, Evans RM, Heyman RA \& Mangelsdorf DJ 1995 LXR, a nuclear receptor that defines a distinct retinoid response pathway. Genes and Development $\mathbf{9}$ 1033-1045.

Wu Q, Liu S, Ye XF, Huang ZW \& Su WJ 2002 Dual roles of Nur77 in selective regulation of apoptosis and cell cycle by TPA and ATRA in gastric cancer cells. Carcinogenesis 23 1583-1592.

Zhang XK 2002 Vitamin A and apoptosis in prostate cancer. Endocrine Related Cancer 9 87-102.

Zhu Y, Qi C, Jain S, Rao MS \& Reddy JK 1997 Isolation and characterization of PBP, a protein that interacts with peroxisome proliferator-activated receptor. Fournal of Biological Chemistry 272 25500-25506.

Zhu Y, Qi C, Jain S, Le Beau MM, Espinosa R 3rd, Atkins GB, Lazar MA, Yeldandi AV, Rao MS \& Reddy JK. 1999 Amplification and overexpression of peroxisome proliferator-activated receptor binding protein (PBP/PPARBP) gene in breast cancer. PNAS 96 10848-10853.

Received in final form 27 December 2004 Accepted 19 January 2005 